\title{
Alacrimia-choreoathetosis-liver dysfunction syndrome
}

INSERM

\section{Source}

INSERM. (1999). Orphanet: an online rare disease and orphan drug data base. Alacrimiachoreoathetosis-liver dysfunction syndrome. ORPHA:404454

Alacrimia-choreoathetosis-liver dysfunction syndrome is a rare, genetic, inborn error of metabolism disorder characterized by global developmental delay, hypotonia, choreoathetosis, hypo-/alacrimia, and liver dysfunction which manifests with elevated liver transanimases and hepatocyte cytoplasmic storage material or vacuolization on liver biposy. Additional features reported include acquired microcephaly, hypo-/areflexia, seizures, peripheral neuropathy, intellectual and language/speech disability, additional ocular anomalies and EEG and brain imaging abnomalities. 